\section{National Diabetes Month - November 2018}

November is National Diabetes Month. In the United States, approximately 30 million persons are living with diabetes and 84 million with prediabetes (1). Persons with prediabetes are at high risk for developing type 2 diabetes, heart disease, and stroke (2). Likewise, women who have had gestational diabetes (diabetes during pregnancy) are at increased risk for developing type 2 diabetes later in life (2). However, type 2 diabetes can be prevented or delayed through a structured lifestyle change program that promotes weight loss, healthy eating, and increased physical activity (2). A report on changes in gestational diabetes in the United States is included in this issue of $M M W R$ (3).

CDC plays a crucial role in preventing type 2 diabetes and diabetes complications. CDC released an action guide to help pharmacists reach persons at risk for type 2 diabetes who could benefit from the National Diabetes Prevention Program (https://www.cdc.gov/diabetes/prevention). In collaboration with partners, CDC launched "Your Health with Joan Lunden and CDC," a broadcast miniseries that explores prediabetes and diabetes issues (https://www.cdc.gov/diabetestv), and the first national prediabetes awareness campaign (https://www. DoIHavePrediabetes.org) to encourage persons to learn their prediabetes risk. More information is available at https://www.cdc.gov/diabetes.

\section{References}

1. CDC. National diabetes statistics report, 2017. Atlanta, GA: US Department of Health and Human Services, CDC; 2017. https:// www.cdc.gov/diabetes/data/statistics/statistics-report.html

2. Venkat Narayan KM, Williams D, Gregg EW, Cowie C, eds. Diabetes public health: from data to policy. New York, NY: Oxford University Press; 2011.

3. Deputy NP, Kim SY, Conrey EJ, Bullard KM. Prevalence and changes in preexisting diabetes and gestational diabetes among women who had a live birth—United States, 2012-2016. MMWR Morb Mortal Wkly Rep 2018;67:1201-7.

\section{Prevalence and Changes in Preexisting Diabetes and Gestational Diabetes Among Women Who Had a Live Birth - United States, 2012-2016}

\author{
Nicholas P. Deputy, $\mathrm{PhD}^{1,2}$; Shin Y. Kim, MPH${ }^{1}$; \\ Elizabeth J. Conrey, $\mathrm{PhD}^{1,3}$; Kai McKeever Bullard, $\mathrm{PhD}^{4}$
}

Diabetes during pregnancy increases the risk for adverse maternal and infant health outcomes. Type 1 or type 2 diabetes diagnosed before pregnancy (preexisting diabetes) increases infants' risk for congenital anomalies, stillbirth, and being large for gestational age (1). Diabetes that develops and is diagnosed during the second half of pregnancy (gestational diabetes) increases infants' risk for being large for gestational age (1) and might increase the risk for childhood obesity (2); for mothers,

\section{INSIDE}

1208 Hepatitis A Virus Outbreaks Associated with Drug Use and Homelessness - California, Kentucky, Michigan, and Utah, 2017

1211 Violence Victimization, Substance Use, and Suicide Risk Among Sexual Minority High School Students — United States, 2015-2017

1216 Update: Recommendations of the Advisory Committee on Immunization Practices for Use of Hepatitis A Vaccine for Postexposure Prophylaxis and for Preexposure Prophylaxis for International Travel

1221 Notes from the Field: Intestinal Colonization and Possible latrogenic Botulism in Mouse BioassayNegative Serum Specimens — Los Angeles County, California, November 2017

1223 QuickStats

Continuing Education examination available at https://www.cdc.gov/mmwr/cme/conted_info.html\#weekly.

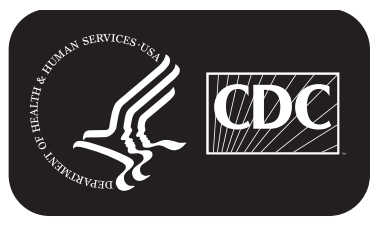

U.S. Department of Health and Human Services Centers for Disease Control and Prevention 